\title{
MMW-HOTLINE
}

Leser der MMW können sich mit allen Fragen zur Abrechnung und Praxisführung an Helmut Walbert, Facharzt für Allgemeinmedizin, Würzburg, wenden. Sie erreichen inn jeden Donnerstag von 13 bis 15 Uhr unter der

kostenlosen Rufnummer (0800) 2379830 oder per E-Mail: w@lbert.info.

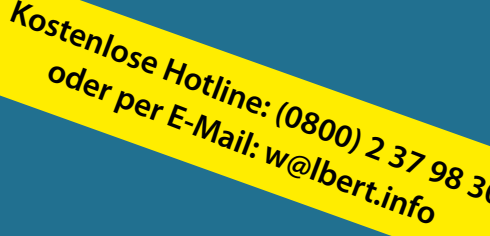

Kollege macht überwiegend Hausbesuche

\section{Kann das zu Problemen führen?}

Dr. med. L., Allgemeinärztin, Würzburg Wir sind zu zweit in einer fachgleichen Gemeinschaftspraxis tätig. Einer von uns macht überwiegend Hausbesuche. Kann das zu Problemen führen?

Antwort: Grundsätzlich ja. Auch in einer fachgleichen Berufsausübungsgemeinschaft (BAG), wie die "Gemeinschaftspraxen" jetzt offiziell heißen, müssen die Leistungen grundsätzlich mit der LAN (Lebenslange Arzt-Nummer) des Arztes gekennzeichnet werden, der die jeweilige Leistung erbringt. Es kommt im Wesentlichen auf die Praxisgröße/Fallzahl an. Jetzt, da die Hausarzt-Verträge größtenteils gekündigt sind, kommt die Plausibilität in Bezug auf die Arbeitszeit wieder stärker zum Tragen. Die Prüfzeit für einen Hausbesuch beträgt 15 Minuten. Dazu kommt häufig die Versichertenpauschale. Diese hat eine durchschnittliche Prüfzeit von 20 Minuten auf das Quartalsprofil.

Nach den Vorgaben darf der Vertragsarzt regelhaft nicht mehr als zwölf Stunden pro Tag oder 780 Stunden im Quartal Leistungen mit „Prüfzeiten“ abrechnen. Wenn Sie mehr Leistung erbringen, kann eine Plausibilitätsprüfung drohen. Sie müssen dann nachweisen, dass die abgerechneten Leistungen plausibel und entsprechend dem Wirtschaftlichkeitsparagrafen 12 des SGV erbracht wurden.

\section{Trotzdem moniert die Kasse den „Behandlungsfall“}

\section{Dr. H. J.W., Dermatologe, KVWL:}

Ich habe immer wieder bei meinen Privatliquidationen das Problem, dass angeblich "der Behandlungsfall“ nicht eingehalten wurde. Wir achten bereits beim Wiedereinbestellen auf den exakten Abstand von vier Wochen. Insbesondere die Postbeamtenkrankenkasse moniert auffällig häufig den so genannten Behandlungsfall.

Antwort: Der Fehler dürfte im kleinen Unterschied der Alltagsdefinition vom Vier-Wochen-Abstand liegen: „Kommen Sie heute in vier Wochen wieder", heißt für Patienten und Mitarbeiter: War der Patient an einem Donnerstag da, wird er exakt wieder am Donnerstag in vier Wochen einbestellt. Die Gebührenordnung ist jedoch ein juristisches Konstrukt und zählt diesen Donnerstag noch innerhalb dieser Vier-Wochen-Frist. Genau lautet der Text im Abschnitt B der GOÄ "Grundleistungen und allgemeine Leistungen" bei den Allgemeinen Bestimmungen unter 1. :

„Als Behandlungsfall gilt für die Behandlung derselben Erkrankung der Zeitraum eines

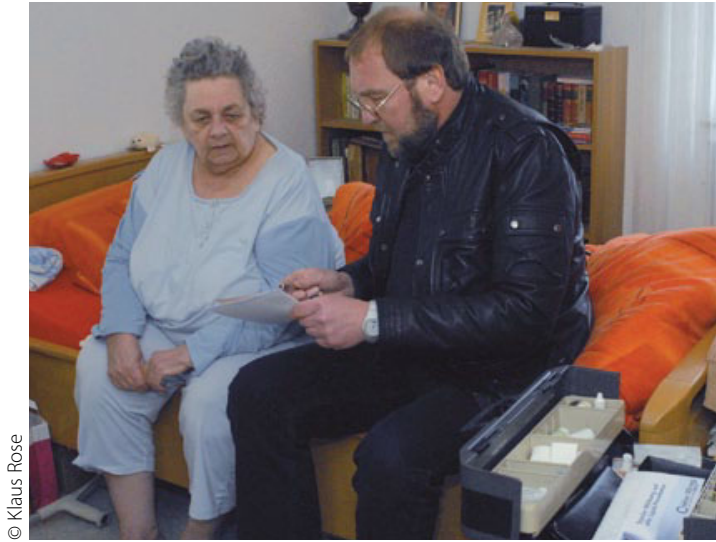

Für Hausbesuche gelten strenge Prüfzeiten.
Helmut Walbert

Allgemeinarzt Medizinjournalist und Betriebswirt Medizin 